\title{
Response to the Valsalva Maneuver After the Fontan Procedure for Tricuspid Valve Atresia, Single Ventricle or Pulmonic Valve Atresia
}

\author{
SAMUEL S. GIDDING, MD, AMNON ROSENTHAL, MD, \\ ALBERT P. ROCCHINI, MD, and MACDONALD DICK, MD
}

\begin{abstract}
The Valsalva maneuver was performed during cardiac catheterization in 9 patients who had undergone a Fontan operation (Fontan group) and in 10 control subjects. The Fontan group had higher right atrial (RA) pressure (16 \pm 1 vs $4 \pm 0.5 \mathrm{~mm} \mathrm{Hg}$, p $<0.001)$, lower cardiac index $(2.5 \pm 0.1$ vs $3.7 \pm 0.2$ liters $\left./ \mathrm{min} / \mathrm{m}^{2}, \mathrm{p}<0.05\right)$, lower stroke index (32 \pm 2 vs $44 \pm 2 \mathrm{ml} / \mathrm{beat} / \mathrm{m}^{2}, \mathrm{p}<0.05$ ), and higher systemic vascular resistance ( $31 \pm 1$ vs $24 \pm 1$ units, $p<0.05$ ) than the control group. Four patients in the Fontan group had a normal 4-phase Valsalva response, and 5 did not $(p<0.05)$. RA pressure was similar in those who responded normally and those
\end{abstract}

who did not ( $16 \pm 0.5$ vs $17 \pm 1 \mathrm{~mm} \mathrm{Hg}$ ), whereas in those who responded normally cardiac index was higher $\left(2.9 \pm 0.2\right.$ vs $2.2 \pm 0.1$ liters $/ \mathrm{min} / \mathrm{m}^{2}, p$ $<0.05)$, stroke index was higher ( $36 \pm 1$ vs $28 \pm 1$ $\mathrm{ml} / \mathrm{beat} / \mathrm{m}^{2}, \mathrm{p}<0.05$ ), and systemic vascular resistance was lower $(28 \pm 1$ vs $31 \pm 1, p<0.05)$. It is concluded that cardiac output is a better predictor of a normal response to the Valsalva maneuver than RA pressure in patients after the Fontan procedure. A normal response to the supine Valsalva maneuver suggests a cardiac index greater than $2.4 \mathrm{liters} / \mathrm{min} / \mathrm{m}^{2}$ and stroke index greater than 31 $\mathrm{ml} / \mathrm{beat} / \mathrm{m}^{2}$.
(Am J Cardiol 1985;56:905-909)
The Valsalva maneuver-maximal expiration against a closed glottis - -is considered an excellent physiologic test for congestive heart failure.$^{1-4}$ During the maneuver, systemic venous return is obstructed, cardiac output decreases, and a reflex increase in systemic vascular resistance and heart rate occur. After release of strain, cardiac output increases and a characteristic overshoot in aortic pressure and pulse pressure occurs, as does reflex bradycardia. In patients with congestive heart failure, systemic venous return is not effectively diminished and a "square-wave response" with absence of the overshoot is observed (Fig. 1).

Elevated right atrial (RA) pressure and low cardiac output have been associated with an abnormal response to the maneuver. ${ }^{1-3,5,6}$ Patients who have undergone the Fontan operation for repair of congenital heart disease (direct RA-to-pulmonary trunk or RA-to-right ventricle communications) usually have elevated RA pressure or

From the Division of Pediatric Cardiology, C.S. Mott Children's Hospital, University of Michigan, Ann Arbor, Michigan. Manuscript received March 1, 1985; revised manuscript received May 23, 1985, accepted May 24, 1985.

Address for reprints: Amnon Rosenthai, MD, C.S. Mott Children's Hospital, F1115, Box 66, Ann Arbor, Michigan 48109. low cardiac index as sequelae of the operation. ${ }^{7-10} \mathrm{We}$ performed the Valsalva maneuver in patients who had undergone successful repair by Fontan operation to determine if a normal aortic pressure response to the Valsalva maneuver is present, and if so, whether the patient's RA pressure or cardiac output are a better determinant of the normal response.

\section{Methods}

The Valsalva maneuver was performed in 19 patients during routine diagnostic cardiac catheterization. A Fontan or modified Fontan operation was performed in 9 patients ( 6 for tricuspid atresia, 2 for single ventricle and 1 for pulmonary atresia with intact ventricular septum). Ten patients served as control subjects. Mild congenital heart disease was present in 5 (mild aortic stenosis in 2 and mild pulmonic stenosis, mitral valve prolapse and cervical aortic arch in 1 patient each) and 5 werc undergoing electrophysiologic study for localization of an accessory bypass tract. The mean age of patients with a Fontan operation was $15 \pm 2$ years and that of control subjects was $15 \pm 1$ years. 'T'he mean interval between operation and cardiac catheterization in the Fontan group was 3 \pm 1 years. The operation performed was RA-to-pulmonary artery anastomosis in 7 patients, $R A$ to right ventricular anastomosis in 1 patient and RA to pulmonary artery valved 
TABLE I Hemodynamic Values at Rest in the Fontan Group and the Control Group

\begin{tabular}{lccc}
\hline & $\begin{array}{c}\text { Fontan Group } \\
(n=9)\end{array}$ & $\begin{array}{c}\text { Control Group } \\
(n=10)\end{array}$ & p Value \\
\hline $\begin{array}{c}\text { Change in PAP, } \\
\text { end strain (phase II } \\
\text { to phase III) (mm Hg) }\end{array}$ & $46 \pm 7.0$ & $36 \pm 4.0$ & NS \\
$\begin{array}{c}\text { Mean RAP } \\
\text { (mm Hg) }\end{array}$ & $16 \pm 1$ & $4 \pm 0.5$ & $<0.001$ \\
$\begin{array}{c}\text { Cardiac index } \\
\left.\text { (liters/min } / \mathrm{m}^{2}\right)\end{array}$ & $2.5 \pm 0.1$ & $3.7 \pm 0.2$ & $<0.05$ \\
$\begin{array}{c}\text { Stroke index } \\
\left(\mathrm{ml} / \text { beat } / \mathrm{m}^{2}\right)\end{array}$ & $32 \pm 2$ & $44 \pm 2$ & $<0.05$ \\
$\begin{array}{c}\text { SVR } \\
\text { (Wood units) }\end{array}$ & $31 \pm 1$ & $24 \pm 1$ & $<0.05$ \\
\hline
\end{tabular}

NS = not significant; $\mathrm{PAP}=$ pulmonary artery pressure; $\mathrm{RAP}=$ right atrial pressure; SVR = systemic vascular resistance.

conduit in 1. This latter conduit was stenotic (15-mm Hg mean gradient) at the time of catheterization. In the Fontan group, 3 paticnts werc in Now York Hcart $\Lambda_{\text {ssociation }}$ (NYH $\Lambda$ ) functional classification class I, 3 were in class II and 3 were in class III. All control patients were class I.

All patients were supine. In each patient resting values of heart rate (average of $3 \mathrm{RR}$ intervals), aortic pressure, RA pressure, pulmonary artery pressure and left ventricular end-diastolic pressure were simultaneously measured. Cardiac output was determined by thermodilution and indexed to body surface area. Stroke index and systemic vascular resistance were calculated. In 7 patients in the Fontan group left ventricular ejection fraction was determined from the left ventricular cineangiograms using Simpson's rule.

To perform the Valsalva maneuver each patient was asked to place his thumb in his mouth and expire maximally without allowing any air to escape. The maneuver was sustained until

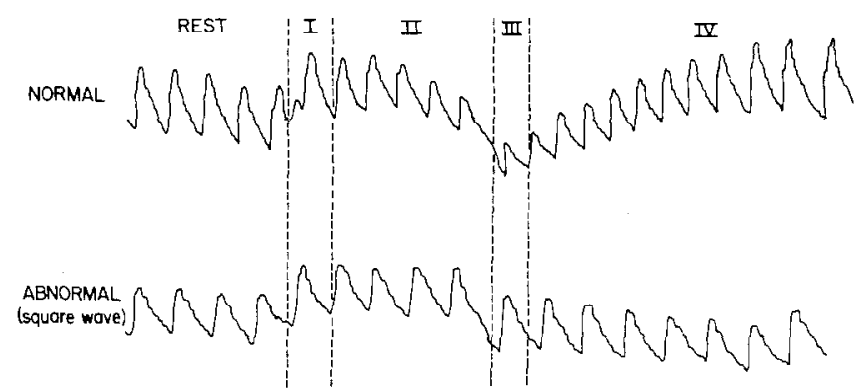

FIGURE 1. Normal and abnormal aortic pressure responses to the Valsalva maneuver in patients after Fontan operation. Phase I represents the onset of strain. Phase II, which has been shortened, represents the maintenance of strain. Phase III is the release of the strain. Phase IV is referred to as the overshoot period. In the normal response during phase I, there is an immediate increase in systolic blood pressure, corresponding to the increase in transthoracic pressure. In phase II, systemic venous return is obstructed by the increased transthoracic pressure. As a result, systollc blood pressure and pulse pressure fall. Heart rate and systemic resistance increase as cardiac output decreases. During phase III, systolic pressure decreases well below values at rest, reflecting the decrease in transthoracic pressure and cardiac output. Pulse pressure remains low and tachycardia persists. In phase IV, systemic venous return and cardiac output rapidly increase, causing an increase in systolic pressure and pulse pressure. These pressures increase above values at rest because of the increased systemic resistance and produce a reflex bradycardia. In the patient with congestive heart failure, the obstruction to venous return does not alter cardiac performance. Therefore, pulse pressure and heart rate remain constant during phase II, and return to baseline values at end strain, giving the characteristic "square-wave" appearance to the response curve. the characteristic rise and plateau in aortic diastolic pressure was observed, indicating an increase in peripheral resistance. Total duration of effort was between 10 and 15 seconds. Heart rate, aortic pressure and pulmonary artery pressure were recorded throughout the effort and for 20 cardiac cycles thereafter. Effort was assessed by measuring the decline in pulmonary artery systolic pressure (or a-wave) at the release of strain. This decrease was considered to reflect transthoracic pressure induced by the strain since there is no significant change in cardiac output at the transition from end strain (phase II) to release (phase III). ${ }^{11,12} \mathrm{~A}$ difference of more than $20 \mathrm{~mm} \mathrm{Hg}$ indicated a satisfactory effort (Table I). The response to the Valsalva maneuver was quantitated by assessing changes in aortic systolic pressure, aortic pulse pressure and heart rale during the maneuver (Fig. 2). For each variable, the difference from values at rest was determined at the release of strain (phase III) and at the peak pulse pressure during the overshoot (phase IV). The number of beats from release of the strain to peak pulse pressure was calculated for each patient with a normal response curve. A normal response curve was defined as having all 4 phases of the characteristic response present for each variable (systolic pressure, pulse pressure and heart rate). All other responses were classified as abnormal.

Within each group, mean and standard error of the mean were calculated for each variable at rest. The Fontan group was further subdivided into normal and abnormal responders. Group comparisons were made using the unpaired $t$ test. A level of 0.05 was selected as the criterion for significance of a positive result.

\section{Results}

Hemodynamic values measured at rest are presented in Table I. The Fontan group has significantly higher mean RA pressure, lower cardiac index, lower stroke index and higher systemic vascular resistance than the control group. Systolic blood pressure at rest (114 \pm 3

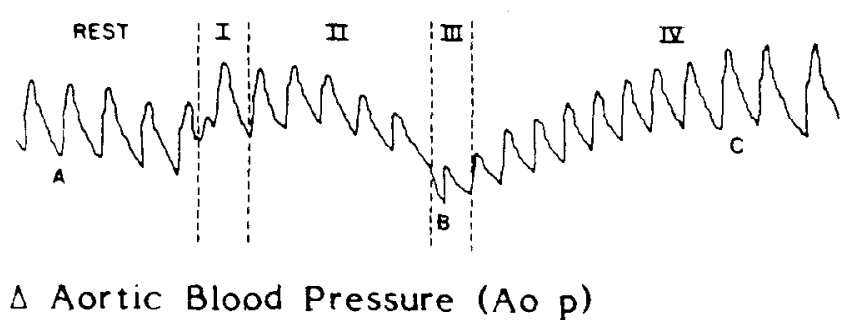

\section{a) Ao p phase III - Ao p rest \\ b) Ao p phase IV - Ao p rest \\ $\triangle$ Aortic Pulse Pressure (Ao pp)
a) Ao pp phase III - Ao pp rest
b) Ao pp phase IV - Ao pp rest

\section{Beats to Peak Ao pp}

FIGURE 2. Calculation used to quantitate the shape of the Valsalva response curve. A, B and C demonstrate the beats selected to make measurements of systolic pressure, pulse pressure and beats to peak pulse pressure respectively. Heart rate was calculated as the average of 3 RR intervals before strain, at phase III, and during reflex bradycardia. 
vs $119 \pm 3 \mathrm{~mm} \mathrm{Hg})$, pulse pressure ( $34 \pm 3$ vs $37 \pm 2 \mathrm{~mm}$ $\mathrm{Hg}$ ) and heart rate ( $78 \pm 5$ vs $86 \pm 4$ beats $/ \mathrm{min}$ ) were similar in both groups. Whereas all 10 control patients had a normal 4-phase response to the maneuver, 4 Fontan patients had a normal response and 5 had an abnormal response (Fig. 3). At end strain (phase III), patients in both control and Fontan groups with a normal response had a similar decrease in systolic pressure ( $40 \pm 5$ vs $37 \pm 9 \mathrm{~mm} \mathrm{Hg}$ ), decrease in pulse pressure ( $18 \pm 2$ vs $25 \pm 4 \mathrm{~mm} \mathrm{Hg}$ ), and increase in heart rate ( $29 \pm 4$ vs $20 \pm 4$ beats $/ \mathrm{min}$ ) (differences not significant [NS]). During the overshoot (phase IV) these groups had similar (NS) increases in systolic pressure $(27 \pm 4 \mathrm{vs} 30 \pm 4 \mathrm{~mm} \mathrm{Hg}$ ), and pulse pressure $(17 \pm 3 \mathrm{vs}$ $20 \pm 2 \mathrm{~mm} \mathrm{Hg}$ ); reflex bradycardia $(-21 \pm 3 \mathrm{vs}-21 \pm$ $4 \mathrm{beats} / \mathrm{min}$ ). However, the number of beats to peak pulse pressure during the overshoot was significantly lower in the control group ( $9 \pm 1$ vs $12 \pm 1$ beats, $p$ $<0.05$ ), suggesting delayed transmission of the systemic venous return to the left heart in the Fontan group.
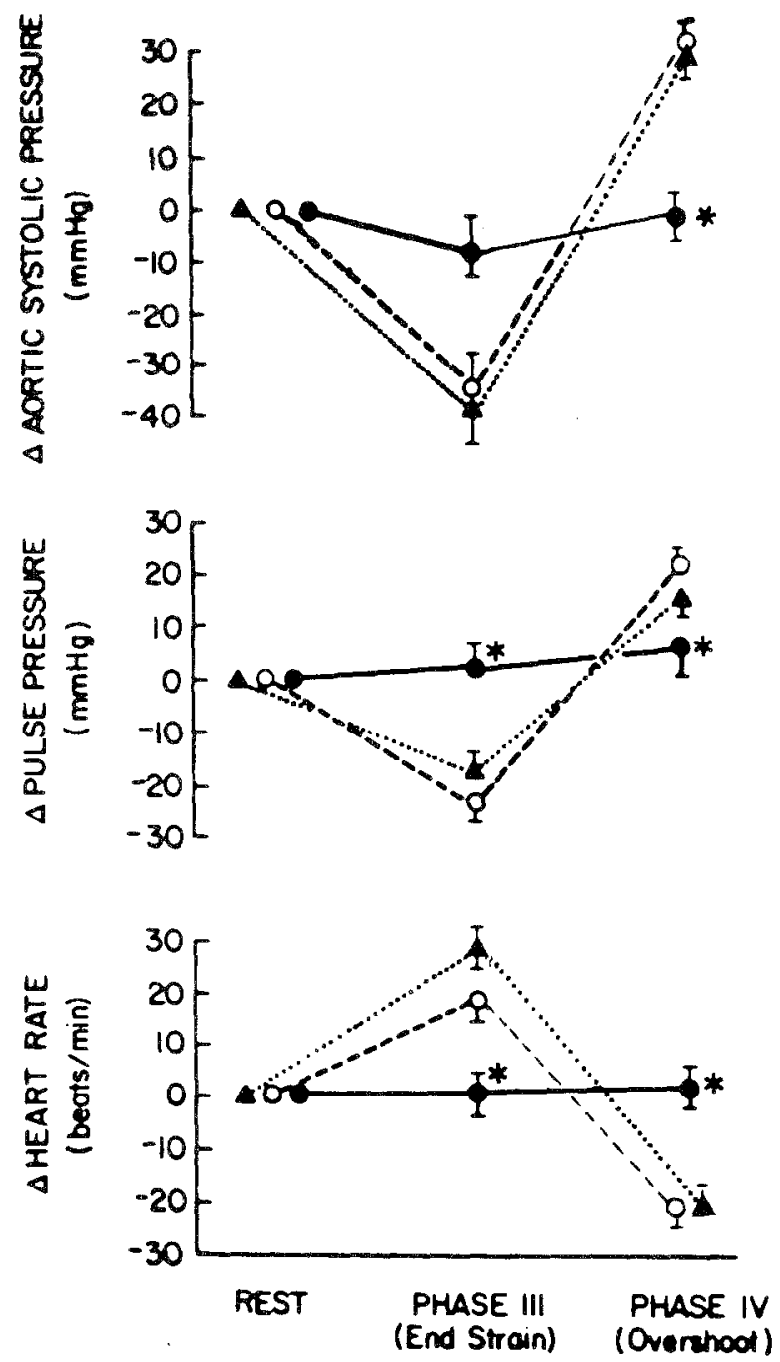

FIGURE 3. Change from values in response to the Valsalva maneuver in 3 groups: control patients (triangles), Fontan patients with a normal qualitative response (circles) and Fontan patients with an abnormal response (dots). Statistical differences ( ${ }^{*} p<0.05$, Fontan abnormal response group vs control group) were found between the control group and the group with an abnormal response in aortic systolic pressure, pulse pressure and heart rate at end strain and during the overshoot.
The 5 patients in the Fontan group with an abnormal Valsalva response had no significant change from rest values to the release of strain or during the overshoot in systolic pressure $(-6 \pm 8 \mathrm{~mm} \mathrm{Hg}$, end strain; $-2 \pm 4$ $\mathrm{mm} \mathrm{Hg}$, overshoot), pulse pressure $(1 \pm 6 \mathrm{~mm} \mathrm{Hg}$, end strain; $5 \pm 2 \mathrm{~mm} \mathrm{Hg}$, overshoot), or heart rate $(2 \pm 3$ beats/min, end strain; $3 \pm 2$ beats/min, overshoot). Compared with patients in the control group, patients in the Fontan group with an abnormal response had statistically different systolic pressure, pulse pressure and heart rate responses at end strain and during the overshoot (Fig. 3).

Figure 4 is a comparison of RA pressure, cardiac index, stroke index and systemic vascular resistance between the 2 Fontan groups. RA pressure did not differ significantly between the 2 groups ( $16 \pm 0.5$ vs $17 \pm 1$ $\mathrm{mm} \mathrm{Hg}$ ); however, those with a normal response had a higher mean cardiac index $(2.9 \pm 0.2$ vs $2.2 \pm 0.1$ liters $\left./ \mathrm{min} / \mathrm{m}^{2}, \mathrm{p}<0.05\right)$ and higher stroke index $(36 \pm$ $1 \mathrm{vs} 28 \pm 1 \mathrm{ml} /$ beat $/ \mathrm{m}^{2}$, p <0.05). A cardiac index of 2.4 liters $/ \mathrm{min} / \mathrm{m}^{2}$ or less and a stroke index less than 31 $\mathrm{ml} / \mathrm{beat} / \mathrm{m}^{2}$ were associated with an abnormal Valsalva response. Systemic vascular resistance was also significantly lower in the normal response group ( $28 \pm 1$ vs 31 \pm 1 units, $p<0.05$ ). In both groups mcan left ventricular end-diastolic pressure was $8 \pm 1 \mathrm{~mm} \mathrm{Hg}$. Among the 7 patients with Fontan operation in whom an ejection fraction was measured, the 3 patients with the highest ejection fractions $(70 \%, 76 \%$ and $78 \%$ ) had a normal response to Valsalva maneuver and 4 (range 31 to $61 \%$ ) had an abnormal response. Three of the 4 patients with a normal responsc werc in NYHA functional classification I and 1 patient was in class II. All patients who
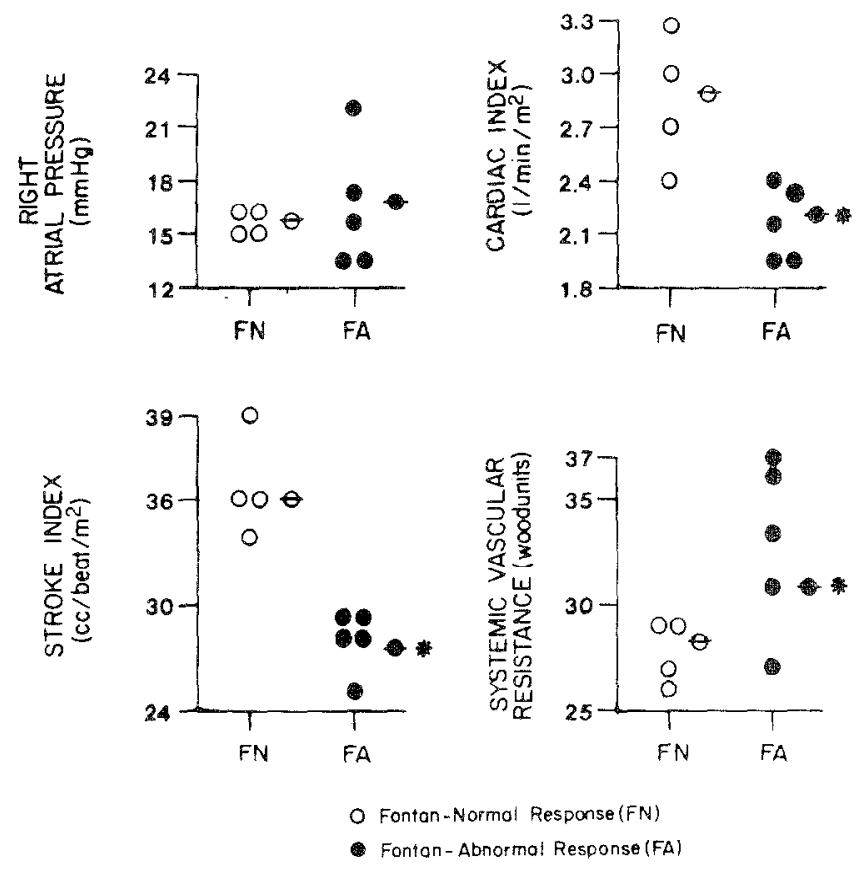

FIGURE 4. Hemodynamic measurements at rest in Fontan patients with a normal response to the Valsalva maneuver (circles) and those with an abnormal response (dots). Crossed symbols represent mean values. Right atrial pressure was similar in both groups. However, cardiac index and stroke index were statistically higher and systemic vascular resistance was lower $\left({ }^{*} p<0.05\right)$ in the normal response group. 
responded abnormally were in functional class II or greater. Thus, in our patients who have undergone a Fontan operation, response to the Valsalva maneuver is independent of RA pressure and appears to be related to cardiac performance as reflected by assessment of cardiac output, stroke volume, ejection fraction and NYHA functional classification.

\section{Discussion}

The Valsalva maneuver initiates a complex sequence of hemodynamic and reflex responses in the normal ${ }^{13}$ subject (Fig. 1) and fails to initiate this sequence in the patient with congestive heart failure because systemic venous return is not sufficiently obstructed during the maneuver. $3,5,11,12$ The characteristic fall in systolic pressure and pulse pressure below baseline at the release of strain, subsequent overshoot of systolic pressure and pulse pressure, and reflex heart rate responses are absent in the latter group. Several studies indicate that elevated RA pressure and right ventricular dysfunction cause an abnormal response to the Valsalva maneuver. An abnormal response has been found in patients with right ventricular failure secondary to cor pulmonale or pulmonic stenosis. ${ }^{1-3}$ Judson et $\mathrm{al}^{2}$ correlated the presence of an abnormal response with elevation of right ventricular end-diastolic pressure and speculated that patients with left-sided heart failure or left-sided obstruction would not develop an abnormal response unless elevations of right ventricular end-diastolic pressure were also present. By producing an acute volume load in patients with a normal response and thus increasing RA pressure, Judson changed the response to a "square wave." Conversely, maneuvers that diminished RA pressure, such as venesection or the placement of thigh cuffs altered abnormal responses to normal. O'Neill and Cudkowicz ${ }^{6}$ studied patients with normal and abnormal responses to Valsalva maneuver and demonstrated elevated RA pressures (mean $16 \mathrm{~mm} \mathrm{Hg}$ ) in patients with an abnormal response. Wilkinson et $\mathrm{a}^{5}$ performed Valsalva-like maneuvers in anesthetized dogs and studied the effects of changes in blood volume and RA pressure. They concluded that an abnormal response could be induced by increasing central blood volume. Elevation of RA pressure produced by the increased blood volume increased effective RA pressure (RA pressure - transthoracic pressure), prevented obstruction of venous return, and thus caused an abnormal response to the maneuver.

Because patients who have undergone a Fontan operation have elevated RA pressures ${ }^{7-10,14-16}$ and either lack or have a poorly functioning right ventricular pump, the above clinical and experimental studies would suggest that patients should have an abnormal response to the Valsalva maneuver after they undergo the Fontan procedure. Why, then, did 4 of our 9 patients have a normal response? The data suggest that the most important determinant is left ventricular performance. The Fontan operation establishes an essentially passive channel between the systemic venous return and the pulmonary circulation. Pulmonary flow and RA pressure are, in large measure, dependent on left ventricular end-diastolic pressure, resistance of the pulmonary circulation and resistance of the conduit. RA pressure under these circumstances is expected to be elevated because it will reflect the total resistance to flow. Our patients with elevated RA pressure but higher cardiac index, stroke index, and left ventricular ejection fraction had normal responses to the Valsalva maneuver. We postulate that in those patients, the left ventricle drains the pulmonary vasculature during the strain. Effective RA pressure is sufficiently low to obstruct venous return and remains low because of an effective left ventricular pump. When strain is released, the dammed venous return is transmitted to the left side of the heart, producing overshoot. Patients with low cardiac index because of left ventricular dysfunction will not have low effective RA pressures at the onset of strain and will not effectively drain their pulmonary circulation during the strain. Systemic venous return will not be occluded and cardiac output will remain unchanged, thus producing a "square-wave response."

Patients with right ventricular failure secondary to cor pulmonale or pulmonic stenosis have elevated RA pressures because of obstruction to pulmonary flow, poor right ventricular compliance and increased blood volume in the venous capacitance vessels. ${ }^{17}$ These factors contribute to maintaining a higher effective RA pressure during the Valsalva strain, failure to diminish venous return, and the subsequent abnormal response. ${ }^{2,5}$ Indeed, in 1 of our patients with an obstructed conduit, obstruction contributed to a low cardiac index and an abnormal Valsalva response.

Patients who responded abnormally after the Fontan operation had poorer cardiac function as assessed by cardiac index, stroke index and ejection fraction, but their left ventricular end-diastolic pressures were similar to those of the patients who responded normally and were within the normal range of values. This similar left ventricular end-diastolic pressure value accounts for the similarity in RA pressure between groups (the only exception being that patient with an obstructed valved conduit and RA pressure of $22 \mathrm{~mm} \mathrm{Hg}$ ). The explanation for the similarity in pressures, despite marked differences in measured overall cardiac performance, may relate to the difference in the determinants of left ventricular preload in Fontan patients compared with patients with structurally normal hearts. In the structurally normal heart, left ventricular failure results in pulmonary congestion, elevation of pulmonary venous pressure and, when severe, right ventricular failure. In patients who have undergone the Fontan operation, and have direct RA to pulmonary artery continuity, there is no pulmonary valve and no effective right ventricular pump. When the left ventricle fails, it has not only the pulmonary circulation, but the whole venous capacitance as a reservoir. Thus, a much larger increase in blood volume may be necessary to increase left ventricular end-diastolic pressure in patients who undergo the Fontan procedure. ${ }^{18}$

\section{References}

1. Gorlin R, Knowles JH, Stovey CF. The Valsalva maneuver as a test of cardiac function: pathologic physiology and clinical significance. Am J Med 1957;22:197-212. 
2. Judson WE, Hatcher JD, Wilkins RW. Blood pressure responses to the Valsalva maneuver in cardiac patients with and without congestive heart failure. Circulation 1955;11:889-899.

3. Sharpey-Schafer EP. Effects of Valsalva maneuver on the normal and failing circulation. Br Med $J$ 1955;1:693-695.

4. Zema MJ, Restivo B, Sos T, Sniderman DW, Kline S. Left ventricular dysfunction-bedside Valsalva maneuver. Br Heart J 1980;44:560-569.

5. Wilkinson PF, Stowe DF, Tyberg JV, Parmley WW. Pressure and flow changes during Valsalva-like maneuvers in dogs following volume infusion. Am J Physiol 1977;233:H93-H99.

6. O'Neill A, Cudkowicz L. Effect of 1-norepinephrine on right atrial pressure and "square wave response" to the Valsalva maneuver. Am Heart $J$ 1964;69:220-228.

7. Serratto M, Miller RA, Tatooles C, Ardekani R. Hemodynamic evaluation of Fontan operation in tricuspid atresia. Circulation 1976;54:suppl III:II99-III-101.

8. Behrendt DM, Rosenthal A. Cardiovascular status after repair by Fontan procedure. Ann Thorac Surg 1979;29:322-330

9. Schachar GB, Fuhrman BP, Wang Y, Lucas RV, Lock JE. Rest and exercise hemodynamics after the Fontan procedure. Circulation 1982;65:10431048

10. Laks H, Williams WG, Hellenbrand WE, Freedom RM, Talner NS, Rowe RD, Trusler GA. Results of right atrial to right ventricular and right atrial to pulmonary artery conduits for complex congenital heart disease. Ann Surg
$1980 ; 192: 382-388$.

11. Greenfield RC, Cox RL, Mernandez RR, Thomas C, Schoonmaker FW. Pressure-flow studies in man during the Valsalva maneuver with observations on the mechanical properties of the ascending aorta. Circulation $1967 ; 35: 653-661$.

12. Fox IJ, Crowley WP $\mathbf{J r}$, Grace JB, Wood EH. Effects of the Valsalva maneuver on blood flow in the thoracic aorta in man. J Appl Physiol 1966; 21:1553-1560.

13. Korner PI, Tonkin AM, Uther JB. Reflex and mechanical circulatory effects of graded Vaisalva maneuvers in normal man. J App! Physiol 1976;40: 434-440.

14. Sharratt GP, Johnson AM, Monro JL. Persistence and effects of sinus rhythm after Fontan procedure for tricuspid atresia. Br Heart $\mathrm{J}$ 1979;42: $74-80$.

15. Shemin RJ, Merril WH, Pfeifer JS, Conkle DM, Morrow AG. Evaluation of right atrial-pulmonary artery conduits for tricuspid atresia. J Thorac Carright atrial-pulmonary artery condu
diovasc Surg 1979;77:685-690.

16. Gale AW, Danillson GK, McGoon DC, Wallace RB, Mair DD. Fontan procedure for tricuspid atresia. Circulation 1980;62:91-96

17. Rushmer RF, Conn RD. The cardiac reserve and congestive heart failure. In: Rushmer RF, ed. Cardiovascular Dynamics. 3rd ed. Philadelphia: W.B. Saunders, 1970:506-546.

18. Fontan F, Baudet E. Surgical repair of tricuspid atresia. Thorax 1971;26: $240-248$. 